\title{
'I am How I Consume': The Construction of Identity through Use of the Mobile Telephone
}

\author{
Dinuka Wijetunga
}

\begin{abstract}
Although identity construction has been discussed extensively in relation to consumption, such studies have also been criticised for reducing consumption objects into mere signifiers or symbols of various identities, ignoring the complex meaning construction processes of objects in use. This paper addresses this criticism, through a study of mobile telephone consumption practices in Sri Lanka, by examining how different usage patterns of the mobile telephone could play a role in consumer identity construction processes. The study focuses on three consumer groups: senior business managers, young consumers representing a high socio-economic stratum, and young consumers representing a lower socio-economic stratum. The findings indicate that consumers use differences in consumption patterns as a means of distinguishing their identities from those of others; further, varying the consumption patterns is used by consumers to manage multiple identities of the same individual.
\end{abstract}

Keywords: Consumption patterns; identity construction; multiple identities; mobile telephone

\section{Introduction}

Identity construction has long been considered in consumer behaviour literature as a key function associated with consumption (Arnould \& Thompson 2005, Slater \& Miller 2007). This body of literature is quite extensive and covers many facets of the relationship between consumption and identity, such as products being an extension of one's self (Belk 1988), how consumption objects are related to different social identities (Kleine III, Kleine \& Kernan, 1993), use of objects in distinguishing oneself from others (Hebdige 1988/2000, Jantzen, Østergaard \& Sucena Vieira, 2006), and the management of multiple identities through consumption (Firat \& Venkatesh 1995, Ahuvia 2005,). However, all these studies

Dinuka Wijetunga $\boldsymbol{P h D}$ is a Senior Lecturer, Department of Marketing, Faculty of Management \& Finance, University of Colombo. E-mail: dinuka@mkt.cmb.ac.lk 


\section{NSBM Journal of Management}

Vol. 1, No. 2, July-December, 2015

appear to focus on the role played by different consumption objects, in other words, what one consumes. How different consumption patterns of the same product or service are implicated in constructing one's identity is not discussed. Due to this omission, identity studies have been criticised for reducing objects to the symbolic meanings embodied in them without paying attention to the complexities of products in use and how meanings are created through usage (Slater \& Miller 2007). This paper demonstrates, through a study of mobile telephone use in Sri Lanka, that different consumption patterns of one object are used by consumers in complex ways in order to differentiate their identities from others. Further, consumers also utilize different usage patterns of the same product to manage multiple identities.

In the remainder of the paper the above stated knowledge gap is first established through a review of the literature on the consumption-identity relationship. This is followed by a brief description of the methods adopted in the research, which consisted of a consumer study where data was collected through focus group discussions from three different types of consumers, namely, senior managers and youth belonging to two different social classes. The findings are presented next, followed by a theoretical discussion indicating how concepts previously used to discuss the consumption-identity relationship could be used, albeit with modification in some instances, to theorise the role played by different patterns of consumption, or how consumption items are used, in the processes of consumer identity construction. The paper concludes with implications of the findings for marketing practice and for future research.

\section{Consumer Culture \& Identity}

It has been said that today's society could be termed as a 'consumer society' (Lee 2000, p. ix) where consumption occupies a dominant position in social activity. The latter part of the 20th century witnessed an important shift in the history of consumption practices when, encouraged by advertising, '[w] hat was emerging was not merely a consumer society, but a consumer culture...' (Miles 1998, p. 9, emphasis in original). The distinction here is that in a consumer culture consumption permeates everyday life at a much more significant level than mere prolific consumption (Slater 1997, Miles, 1998). Engaging in an interesting and meaningful word play, Slater (1997, p.24) says that consumer culture is not about '...a particular consumption culture...,' in that it does not refer to '....a particular pattern of needs and objects...' Instead, it refers to a '...culture of consumption...' where '...core social practices and cultural values, ideas, aspirations and identities are defined and oriented in relation to consumption rather than to other social dimensions such as work or citizenship, religious cosmology or military role...' (Slater 1997 p. 24, emphasis in original). 
'I am How I Consume': The Construction of Identity through Use of the Mobile Telephone

This high significance of consumption in social activity has a dual focus (Featherstone 2007, Slater, 1997). First, the high regard accorded to consumption has resulted in a spillover of consumption-related values into non-consumption areas such as education and the public service, where it is advocated that students and the public served by government organizations be treated as 'customers' and their needs as 'sovereign' (Slater 1997, Holt \& Schor 2000, Ritzer \& Slater 2001,). Second, increasingly more areas of social life are being reproduced through the use of commodities (Slater 1997, 2005), where they are used not just as utilities, but as symbolic '...communicators...' (Featherstone 2007, p. 82). In other words, people use consumption objects to signal various different things to themselves and to others (Hill 2002).

Such symbolic meanings are constructed for different products through interactions between the broad socio-cultural meanings of objects, marketing activity (especially advertising) and individual consumption activity (Lee 1993). These symbolic meanings help consumers in constructing identity. As noted by Arnould and Thompson (2005), '...the marketplace has become a preeminent source of mythic and symbolic resources through which people ... construct narratives of identity...' (p. 871). Thus, goods '... are two media of communication: both bulletin boards for internal messages and billboards for external ones...' (McCracken as quoted in Hill 2002, p.274) signalling one's identity to oneself and to others.

\section{Identity Construction, Identity Change \& Multiple Identities}

Identity has generally been conceptualised in two ways: as a psychological, personality characteristic that is enduring over time, or as a fragmented, situationally constructed phenomenon (Hall, 2000, Ybema et al. 2009). Both conceptualisations have featured in studies on the relationship between consumption and identity. An example of the former category is a seminal study on the consumption-identity relationship, where Belk (1988) speaks of consumption as an extension of one's core self. Later research (e.g. Holt 1995, Gould \& Lerman 1998, Ahuvia 2005, Shankar, Therkelsen \& Gram 2008, Elliott \& Fitchett 2009) shows that consumption is also utilised by individuals in the construction of situated and multiple identities. In this latter group, identity is treated as a construction or as a 'presentation, not self' and as 'persona, not personality' (Ybema et al. 2009, p. 306).

This notion of individuals reflexively constructing situated identities is very much in line with discussions of identity in much of the consumer culture literature. Slater (1997, p. 29) notes that in the contemporary post-traditional society the consumer culture has become the '...privileged medium for negotiating identity and status...' He notes that unlike in the 


\section{NSBM Journal of Management}

Vol. 1, No. 2, July-December, 2015

traditional society where one's identity and place in society was assigned to one at birth, in a post-traditional society identity and status are not regulated by tradition, and therefore not given nor fixed. Thus, these need to be 'negotiated' by the individual. The term negotiation is significant as it highlights the fluid nature of identity creation in this culture where '...not only is one's position in the status order no longer fixed, but the order itself is unstable and changing and is represented through ever changing goods and images...' (Slater 1997, p. 30).

Bauman (2001, p. 28) terms this instability of the 'order' as '....institutional erosion coupled with enforced individualization...' He further explains it by comparing the present society with that described by Durkheim. According to Durkheim (Bauman 2001), society was important for man because it represented a sense of permanence compared to the mortality of man. However, asserts Bauman (2001, p. 23),

['S]ociety' has moved from the role of caring, albeit exacting warden/keeper into the position of one of the players.... Once the mainstay of stability and the warrant of assurance, it has become now the prime source of surprise and of a diffuse danger, frightening for its un-knowability...

In these conditions individuals are required to find solutions to the vagaries of a fickle system, and identities are 'projects' that individuals have to undertake and perform (Bauman 2007).

Present day individuals undertake this project primarily through consumption (Slater 2005). People not only use material goods to acquire and express identity, but also to enhance an identity, or in attempting to reach an 'ideal' identity (Dittmar 2008). This has been facilitated not only by the proliferation of consumption goods in society, but also by advertising messages that associate goods with 'idealised images' of people (Dittmar 2008, p. 12). In this scenario, identity becomes a function of consumption rather than the other way round (Slater 1997). This can be clearly identified in the following research excerpt where one research participant speaks of how two different brands of cars symbolise two distinctly different identities:

...Sometimes I test myself. We have an ancient, battered Peugeot, and I drive it for a week. It rarely breaks down, and it gets great mileage. But when I pull up next to a beautiful woman, I am still the geek with the glasses. Then I get back into the Porsche. It roars and tugs to get moving, it accelerates even going uphill at 80 . It leadeth trashy women ... to make pouting looks at me at stoplights. It makes me feel like a tom-cat on the prowl. ... Nothing else in my life compares - except driving along Sunset at night in the 928, with 
'I am How I Consume': The Construction of Identity through Use of the Mobile Telephone

the sodium-vapor lamps reflecting off the wine-red finish, with the air inside reeking of tan glove-leather upholstery ... and with the girls I will never see again pulling up next to me, giving the car a once-over, and looking at me as if I were a cool guy, not a worried over-extended 40 -year-old schnook writer... (Stein as quoted in Belk 1988, p. 145)

Although the above excerpt is about how the consumer experiences different identities, the notion of constructing situated identities also implies a multiplicity of identities actively constructed by the same individual. The place of consumption in such activities has also been discussed in the literature. Some postmodern scholars of consumer culture argue that the notion of a stable, coherent identity is an oppressive myth of modernity (Slater 2005), and present a liberatory view of using consumption to construct multiple identities (Firat \& Venkatesh 1995). They argue that consumers like the ability to change identity at will through their consumption patterns. This indicates a situation where '.... society appears as a kind of fancy-dress party in which identities are designed, tried on, worn for the evening and then traded in for the next...' (Slater 1997, p. 30). However, other consumption studies suggest that people seek to manage multiple identities in some meaningful way rather than use and discard them in arbitrary fashion (Gould \& Lerman 1998, Ahuvia 2005, Arnould $\&$ Thompson, 2005) and that people utilise different consumption strategies to manage the complexities of multiple, and at times, conflicting identities (Ahuvia 2005).

Whether in relation to single or multiple identities, it is useful to examine how the literature portrays consumption activities in consumers' identity construction processes.

\section{The Consumption Modes of Identity Construction}

Some scholars argue that identity studies have presented an overly simplistic picture of consumption:

... One of the less helpful turns taken by consumption studies was the obsession with identity which seemed to reduce all this [i.e. complexities of consumption practices] to the banal question of how to perform a consistent persona, and reduced the object or good to a sign or marker; the object has a materiality only in a semiotic sense: as a signifier. A sign has to have material embodiment, and that's it. Beyond that the good is simply a term within a structure of meaning that individuals (and it's very much individuals) can employ as resources for constructing versions of themselves. It loses the sense of the broader materiality of the object, and it loses the transactional nature of objects and 


\section{NSBM Journal of Management}

Vol. 1, No. 2, July-December, 2015

the fact that they have meaning within relationships which they reproduce...

(Slater \& Miller 2007, p. 19)

The concern of Slater and Miller is well founded because, in the discussions of consumptionidentity relations the consumption objects are usually considered as 'symbolic' resources (Arnould \& Thompson 2005) that help consumers to make use of symbolic meanings associated with the objects in constructing different identities. This is evident in the Porsche vs. Peugeot story above as well as in other research. For example, one study shows how middle class working women distinguished themselves from 'housewives' and 'harlots', based on the brand, colour and material of the underwear they use (Jantzen, et al. 2006, p. 184). Hebdige (1988/2000) explains how the Italian motor scooter that was introduced to the market as a mode of transportation for women was used in a symbolic fashion by the Mods, '... a highly stylized male youth subculture that fancied accoutrements that screamed modern and (slightly) effeminate...' (Holt \& Schor 2000, p. xiv). In the arena of mobile telephones it has been noted that Italian girls use their phone as a fashion accessory where the brand of the phone is an important symbol (Fortunati \& Cianchi 2006). Further, owning a phone itself has been discussed as a symbol of a strong sense of personal identity: '...it is you being called, not your home...' (Carroll, Howard, Peck \& Murphy 2002, p. 57).

The foregoing discussion highlights the preoccupation of identity studies with the symbolic meaning of objects, which tends to ignore the different patterns of usage as well as the meanings objects take up when used in social relations (Slater \& Miller, 2007). However, such complexities can play a role in identity construction. This is because identity construction includes '...bodily acts...' (Ybema et al. 2009, p. 304) which include the use of artefacts. Further, identity construction is a function of inclusion and exclusion (Hall 2000, Ybema et al. 2009) where 'self' is separated from the 'other' through the articulation of similarities and differences. It has been acknowledged in consumption studies that such differences and similarities can be articulated through how one uses the same product or service. For example, Holt's (1995) study of ritualistic practices at baseball games shows that some of the practices could establish affiliations and distinctions between 'expert' baseball fans and mere amateurs. However, Holt (1995) does not discuss such behaviours in the context of identity construction.

Some recent identity research on consumption has remedied the weaknesses highlighted by Slater and Miller (2007) to some extent, especially in terms of consumption meanings constructed in social relations. (For a discussion of recent studies on consumption and 
'I am How I Consume': The Construction of Identity through Use of the Mobile Telephone

identity, see Thompson, 2014.) However, these studies do not focus on how consumption of the same product in different ways could be used in constructing different identities.

This paper, which focuses on mobile telephone consumption by Sri Lankan consumers, demonstrates that consumers utilise different patterns of consumption in constructing different identities; in other words, identities are constructed through how they use the telephone.

\section{Method}

This study was part of a broader research project on advertising and consumption of the mobile telephone in Sri Lanka. It was a social constructionist research, which enabled the researcher to identify how consumers construct different identities for themselves and also differentiate their identities from others through different usage patterns of the mobile telephone. Data collection of this project was from May - August, 2009. Given the speed of change in mobile phones this means that the actual usage practices at the time of publication of this paper are likely be different to the practices during the data collection period. However, the author believes that this does not affect the central argument of the paper, namely, that different usage patterns of the same product could feature in consumers' identity construction processes. Nor does it affect the temporal relevance of the argument to the time of publication since readers could easily relate the presented findings to a variety of different usage patterns, not only of the mobile telephone, but other products as well.

The data was collected from three different types of consumers: senior business managers, and two categories of youth. Business managers have always been a key user group of the mobile telephone (Agar 2003, Vesa 2005); when considering youth, today the phone has become not just a ubiquitous appendage, but also an identity symbol of the young 'Fun Generation' (Vesa 2005, p. 11), hence the use of these consumer groups in the study. In order to capture the socio-economic diversity of users, the author included two categories of youth: One group represented the socio-economic elite of the society, a group that has a high income, is directly exposed to global trends, and displays a conspicuously consumerist and Westernised lifestyle, that has been called the '... New Urban Middle Class...' or NUMC (Liyanage 2009, p. 35). The second group represented a lower socio-economic stratum employed in semi- or unskilled manual work, but are also prone to consumerist behaviours; this group is called the ‘...New Working Class...' or NWC (Liyanage 2009, p. 48).

Focus group discussions were used to collect data where nine discussions comprising three each of the three consumer types were conducted. The number of participants in the groups 
varied between 4-8 members (Barbour 2007, Krueger \& Casey 2000) and comprised both genders. In total there were 16 senior managers (11 male; 5 female), 16 NUMC youth ( 9 male; 7 female), and 16 NWC youth ( 7 male; 9 female). All youth were between 19-25 years of age and were unmarried. Most senior managers (except two males and one female) were married. All discussions were moderated by the author using a broad discussion guideline. Those with NWC youth were conducted, transcribed and analysed in Sinhala; all other discussions were conducted in English. The focus group discussions were analysed using a thematic analysis approach (Braun \& Clarke 2006, 2013).

\section{Findings}

Overall, the findings indicate that in the everyday mundane consumption of the mobile telephone, consumers utilise different usage patterns in complex ways to construct and manage identity. First, by associating different usage patterns with different identities, they construct 'me' vs. 'other' distinctions. Second, by varying usage patterns they also succeed in managing multiple, and at times, conflicting identities. These findings are discussed in detail below:

\section{Differentiating 'Me' from the 'Other'}

\section{The 'Executive'}

In the identity talk of senior business managers, their professional identity was prominent. In talking about this identity they spoke of the mobile phone as a versatile business tool to be in control of work. Such references occurred frequently in the talk, and a number of managers referred to some aspect of this identity in answering the question 'What does the phone say about you?' (i.e. a direct identity-related question). This is seen in the following excerpt:

Vidya $(\mathrm{M})^{1} \quad$...Err I feel that the phone that you carry, especially when you're associating with the business crowd, you're in a different level. Like, some people, you see they're carrying a sophisticated phone, but you find that they can't afford it. Maybe that they are spending somebody else's money to carry it. But in our level, when we move with the

\footnotetext{
In using excerpts from focus group discussions, the following presentation practices are used. Square brackets are used to include any explanatory notes or to present short interjections by others. Ellipses indicates that some sections have been omitted. The speakers will be referred to by a pseudonym followed by ' $M$ ' or ' $F$ ' to identify the gender. Therefore Vidya (M) would mean that Vidya is a male. However, the gender of speakers in the excerpts does not imply that there was gender specific significance in relation to what is discussed. In most instances, there were other similar discussions involving both males and females.
} 
'I am How I Consume': The Construction of Identity through Use of the Mobile Telephone

crowd, you know the business crowd, executive kind crowd, I think the phone talks a lot of about you, ... At the same time you feel proud also because you have all the names and the contact numbers with you, sometimes even the addresses you know. Suddenly even in our top management, sometimes, ask, 'Kulatunga [Vidya's surname] do you have this person's number with you?' 'Yes, I have the number.' 'Can you get him on line?' Sometimes my MD does not have, doesn't carry the numbers of our senior managers. But I have all the numbers. Right? And again, sometimes I have noticed, when my general manager is abroad, he used to give me a call and say, Can you ask that person to contact me? Because he knows that I used to answer quickly. Within one or two rings I used to answer. So that, I feel that has created something about me because of that sort of thing.

Here, construction of the 'executive' identity is very clear. First the speaker refers to himself as belonging to the 'business crowd' and 'executive' crowd and clearly differentiates himself from others who may carry sophisticated phones. He goes on to describe how the phone plays a role in this identity by showing that it has enabled him to be recognised by others as someone with the ability to reach and be reached by the business network, and thereby be in control of work, at all times. Different versions of this practice of being in control of work thorough the phone were given in a number of answers to the question 'What does the phone say about you?' - e.g. '...Basically, it doesn't make a difference whether I'm working in office or out of office. It's the same...' and '... [the phone being switched on 24 hours a day] shows I'm somebody who doesn't want to separate work and personal life. So, it's like work is everything for me...'. Such statements show that this usage pattern of utilising the phone as a tool to be in control of work is important in constructing the business executive identity since it 'says' something important about the person as an executive.

Many managers spoke of communication as a key function (but not the only one) that helps them to keep control of business activity. The phone facilitates this primarily by enabling twoway contactability at all times: one can reach, and be reached by, colleagues and subordinates at all times. There were references to the phone being switched on ' $24 / 7$ ', factories working round the clock, branches in different parts of the world, and contacting people on the field, etc. While this contactability refers mainly to reaching people via phone calls, other features also come into play. For example, as demonstrated in the previous excerpt, one key aspect of being able to reach colleagues and business contacts at any time is the availability of contact 


\section{NSBM Journal of Management}

Vol. 1, No. 2, July-December, 2015

details on the phone; here the phone functions as an address book. In addition, there were other features the managers mentioned in relation to the communication aspect of controlling one's work, such as accessing business email on the phone -functioning as a computer, using SMS templates to send production and sales reports from various locations- functioning as part of a reporting system, and automated SMS alerts linked to computer systems -functioning as a part of an emergency alert system.

Apart from communication, the managers also use the phone and its different features in various other ways in their executive role. For example, some of them use it to access macrobusiness-environment information by subscribing to SMS alert services such as 'Lanka Business Online', or by using the phone to access financial information on the Internet. Some use the voice recorder to record meetings for later reference. There was also mention of using other features such as the camera or the video camera in relation to work activities, and synchronising one's personal organiser on the office desktop with the phone.

All these activities, although utilising common features of the phone, are very specific to the identity of a senior business executive. They describe the senior managers' usage patterns of the mobile phone, namely, using it to stay in control of their work, in relation to the 'executive' identity. It is equally interesting to note how these managers differentiate this identity from others who use mobile phones by referring to certain usage patterns as not only irrelevant for executives, but sometimes even as inappropriate. To a lesser extent, they also referred to their own usage patterns as unique to 'executives'.

\section{The 'Other'vis-à-vis the 'Executive'}

In a mild way the senior managers implied that the way they use the phone as described above is unique to executives. This was mostly done in answer to the question: 'What does the phone say about you?' Some managers declared that merely having a mobile phone can hardly say anything about a person since everyone from 'A/L students' to 'labourers' carry mobile phones these days and 'even low income people can have better phones' than the ones managers carry. However, they noted that some phones such as the BlackBerry may not be attractive to users who are not business executives since the features of these phones would not be relevant to the other users; this is a subtle indicator that certain usage patterns are unique to the executives. Referring to teenagers, one manager stated that '...BlackBerry would not have the attractive features that those other phones have...'. [Note: In 2009, at the time when data was collected, the BlackBerry enjoyed high recognition as a business phone], A similar sentiment was expressed by another manger in the following excerpt: 
'I am How I Consume': The Construction of Identity through Use of the Mobile Telephone

Tharanga (M) ... Say for example, say if you're having a BlackBerry phone that means you are always linked with your office. You don't have to have a BlackBerry phone just to give a call? In that case I think you are linked with the office. You're like a mobile office. Even if you're at home you can contact your office and you can get the things done. So in that sense yes, of course it reflects something about you.

What Tharanga is doing here is connecting the usage patterns related to the executive identity with the symbolic associations of BlackBerry; the BlackBerry becomes a symbol of the business executive because it has features that enable the executive to perform his work. By implication, other phones would have different features facilitating different usage patterns because of which the BlackBerry can differentiate executives from others. It should be noted that although the usage patterns related to the 'business executive' identity dominated the discussions of senior managers, references to that usage pattern being unique to executives was not explicit and usually took subtle forms as shown here. One could speculate that this lack of explicit distinction was probably due to the fact that the practice of establishing their pattern of consumption related to the 'executive' identity was so strong that it hardly needed to be stated as unique.

The explicit distinction between the 'executive' and the 'other' is much more prominent in the managers' references to usage patterns that they do not engage in. One such practice is using the phone for fun and entertainment, particularly through using features such as games and MP3 music players. Often the managers referred to such activities as those of 'kids'. Even the ones who did say they use these features subordinated this fun/entertainment function to the business function of the phone (see the later section on managing multiple identities).

Two other practices that were rejected, but in a more emphatic manner, were changing ringtones and using ring-in tones (a song heard by a caller while waiting for the call to be answered). A number of managers spoke of these practices as things done by children. Here the construction of 'the other' was even clearer, because these practices were considered by some as inappropriate for executives. For example, one manager made this comment on using ring-in tones: 'Customers will call you and you have put an absurd song in your phone and he listens to that; doesn't make you serious.' The following excerpt is another example. It was an answer to the question whether they change ringtones from time to time: 


\section{NSBM Journal of Management}

Vol. 1, No. 2, July-December, 2015

Janadiri (F): My son changes, sometimes. You know a funny thing happened, not to me, a colleague of mine. We were at an important meeting, right? So he goes to, he's from Kandy but works in Colombo and he goes to Kandy at weekends. His son is about, say, I think, 11, 12 years. So he plays with the phone. Suddenly, at the meeting his phone goes 'Rosa polla geneng' [lyrics of a fast paced pop song.] Loudly as ever. [Here she breaks into laughter; as do the others in the group.] That was the tone he [the son] has put for his calls to his father. [More laughter from the group] Still I, [laughs], it was so [laughs]

She went on to say that her colleague was embarrassed, but 'luckily there wasn't anyone from outside, so it was ok.' Thus, not only are practices like changing ringtones and ring-in tones activities of children, but since these tones can be heard by others these 'childish' activities could be harmful to the identity of an executive because it 'doesn't make you serious.'

In this manner, the senior business managers engage in specific patterns of mobile phone usage that they consider as activities related to the work of 'executives,' and at the same time, dissociate themselves from other usage patterns that they connect with those who are not executives (such as 'kids'). This dissociation is very strong in some instances where they consider the usage patterns as inappropriate for executives.

\section{The 'Youth'}

Among the young participants of the study, the predominant identity linked to the phone was that of a 'youth.' In relation to this identity, all the young participants in the study considered the phone as something to 'have fun with'. This is a distinctly different usage pattern to the one associated with the 'executive' identity and includes activities that the senior managers tended to dismiss as practices of 'kids', clearly indicating that both groups of participants associate this usage pattern with the 'youth' identity. The young participants spoke of myriad activities as being fun. In short, doing many things 'with' as well as 'to' the phone is a part of their identity as youth. In the words of one participant: '... Since we are in the young age, [we] use many things on the phone. [We] use everything that is there...' ${ }^{2}$

An example of 'doing many things' associated with the youth identity is doing cosmetic changes 'to' the phone regularly. The young participants frequently change the ringtone and

\footnotetext{
2 The participants were often speaking in colloquial Sinhala without a subject in the sentence, and pronouns have been inserted in appropriate places of the translation to make sentences meaningful. The original statement was:

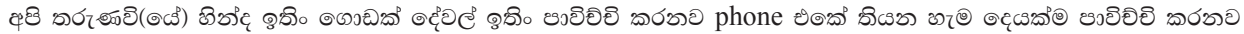


'I am How I Consume': The Construction of Identity through Use of the Mobile Telephone

wallpaper. The following excerpt (key sections italicised) shows that these activities are routinized social behaviours common to their social group. The moderator had asked how often they change ringtones:

Lasitha (M) Every time you find that you like a new song...

Akbar (M) You go hunting, then. You check your friends' mobiles, you go to their gallery, just check whether they have, just check on the list and in case you find something really interesting, ok I'll just try it. I mean just transfer it through Bluetooth. I mean when you meet your friends, you just ask for their mobile phones, and check for new ringtones something like that. And then if you find something interesting, you just transfer it.

The latter part of Akbar's turn shows that checking for songs in the collections on friends' phones is not something one does simply when one is looking for a new song. It's a routine socialising behaviour where one checks the phones of friends for new ringtones to see if there would be something interesting. Also, notice the use of simple present (habitual) tense '...when you meet your friends...', etc., which emphasises the routine nature. It is also significant that throughout this exchange the second person 'you' is used in talking about the practice of looking for new ringtones. Here, it is not used as form of addressing anyone, but as a colloquial form that generalises the statement to include others in addition to oneself. In saying '...you go hunting...' instead of '...I/we go hunting...', Akbar is implying that this is a practice common to others besides himself and the immediate group present at the discussion. Therefore, 'hunting for ringtones' is not idiosyncratic to the speakers but a social behaviour. Thus, even the practices of 'doing things to' the phone, which on the surface appear to be private acts, are in fact shared social activities of these young participants, and hence, part of the identity of being a youth. The shared nature of these activities is exhibited not only in the participants' generalisation of them to a broader group, but also in their practices of exchanging content such as ringtones and wallpaper with one another.

Socialising with peers is prominent in the 'entertaining' usage patterns related to the 'youth' identity. In addition to the exchange of content such as ringtones, songs, pictures and wallpaper, they also use the phone in numerous other ways to socialise. Apart from phone calls and text messages, in a number of groups, there were lengthy and involved discussions regarding the use of 'missed calls' (calling someone and disconnecting the call before the other person answers ) to signal 'I am thinking of you.' Here, they utilize the caller identification and missed call alert facilities to use a phone call as a form of electronic 'calling card'. In one 


\section{NSBM Journal of Management}

Vol. 1, No. 2, July-December, 2015

group, participants also mentioned that they use conference calls to tease one another, using the phone to 'hang out' with friends, even without their physical presence. It is interesting to note that in this manner even some of the features of the phone that senior managers use in their 'business work' are used by these young people in very different usage patterns.

There were some differences between the NUMC youth and NWC youth in their 'fun related' usage of the phone. For example, using the phone to participate in virtual social networks such as the Facebook was prominent in the NUMC talk but totally absent in the NWC talk. In spite of these differences in the specific usage patterns of young participants from the different socio-economic backgrounds, in essence, both groups construct the identity of a 'youth' in the same way: through engaging with the phone as something to have fun with, especially by using it to socialise with peers in entertaining ways.

\section{The 'Other' vis-à-vis the 'Youth'}

Similar to the 'executive' identity, the 'youth' identity was also distinguished from 'the other'; here the distinction was between 'the youth' and 'the adult'. However, unlike in the previous case, the young participants did not dissociate themselves from certain usage patterns. Instead, they clearly identified certain usage patterns as unique to youth. In order to do that they used distinctions in social meanings associated with some practices. Adults were categorised as the out-group because they are ignorant of the social meanings shared among youth in relation to certain practices. This was identified most clearly in relation to the use of missed calls, as shown in the following two excerpts:

\footnotetext{
Moderator So you use missed calls a lot?

Lasitha (M) Yeah

Wasuk (M) Within the social groups it's kind of understood for what it might be and if you know the person

Lasitha (M) Yeah. Sometimes it's 'Hi' and sometimes it's a 'Call me. Only incoming.'

Moderator So how do you know? I mean a missed call is just a ring

Lasitha (M) Depends on that person

Moderator So you know if this one calls, it's because that person is out of credit and this one is telling me

Lasitha (M) Just for fun. Yeah
} 
'I am How I Consume': The Construction of Identity through Use of the Mobile Telephone

The discussion continued where the participants described how they use missed calls. A little later, they were asked if they use missed calls with their parents:

Wasuk (M) They're a bit more orthodox to understand [Laughter from Akbar and Shehani]

Lasitha (M) Yeah

Moderator They won't understand?

Wasuk (M) They'll actually call back. Then it's not the same thing

In the first excerpt the participants construct the in-group in describing how those who belong to the 'social group' can decode the message contained in a missed call. In the next one they construct the parents as belonging to the out-group because parents are too '...orthodox to understand...' that a missed call is just a greeting, and therefore respond by calling back. The laughter that follows emphasises the out-group construction. In a similar discussion in another group of NUMC youth, the out-group - those who do not understand the missed call as a form of greeting - was labelled as '.... g generation up...'. Clearly, the use of 'missed calls' in socialising is a usage pattern that is unique to the 'youth' identity and distinguishes it from that of adults.

\section{The Technophile}

This is a secondary identity constructed by a small number (eight) of male participants in the senior manager groups and the NUMC youth groups. This identity was based on superior knowledge of the mobile phone, which they claimed to result in 'sophisticated' usage patterns. The identity was distinguished from 'others' who only use the phone in 'basic' ways. Superior knowledge of the phone was displayed by these participants in two ways: they regularly interspersed technical terms in their talk and they ventured to teach other focus group participants about the phone. [Note: It should be remembered that these focus groups were conducted in 2009 when 3G was relatively new to Sri Lanka and smart phones were not as ubiquitous as they are today. Much of what the technophiles talk about was new at the time, but is common knowledge today.] 


\section{NSBM Journal of Management}

Vol. 1, No. 2, July-December, 2015

The following is an example of the heavy use of technical terms (key sections italicized):

Husain (M) Earlier we were using GPRS. That the speed is very low. Like $3 \mathrm{G}$, the speed is high. The packet data speed is higher than the GPRS. So that when you go to Gmail and say to chat or something, in a normal phone also, it' 11 be more faster and, since it has $3 \mathrm{G}$, more faster and

Moderator So you're happy that you've moved over to 3G? That it's giving you a better service?

Husain (M) Yeah, yeah. Now it's 3.5G. 3G is outdated. 3.5G is exactly what is HSPA [This is a reference to a previous part of the discussion where he had explained the technology called HSPA]

Notice how Husain doesn't stop at saying 3G is faster. He provides a more technical explanation referring to '...packet data speed...'. Admittedly, some of the technical terms such as GPRS and 3G etc. are used today in everyday ordinary conversations. However, there was a greater use of technical terms in the talk of the technophiles compared to other participants. For example, 'HSPA' and 'packet data' are not terms that are generally used in casual conversations. Similarly other technophiles also used terms such as 'mini-SD' and 'micro-SD' which were not used by any of the other participants.

The technophiles educated others by providing detailed information about various features of the phone including information about other participants' phones.Notice how, in the following excerpt from an NUMC youth group, the participant is providing information about a feature that he is not using. This is significant because the participants were informed at the beginning of the discussions that it was a discussion about the different ways in which they use the mobile phone, and the discussion questions were also all relating to how they use it. Yet, there were many instances when the technophiles provided information about features they don't use:

Pasindu (M) And I don't use the programme, but I have a, I have an application called Google Maps I'm sure you've heard about it. Like that has an option called latitude. It's for people to keep, like basically, if I add you like and if you agree to it, if you lend me your rights basically, then I can see where you are. So this is used for families and like if there is an issue. So my girlfriend, she has a sister. They both have it, and they know exactly where each other are and that's good 
'I am How I Consume': The Construction of Identity through Use of the Mobile Telephone

Notice how Pasindu begins his turn saying '...I don't use the programme...' and then gives a detailed explanation about how the programme works. What is even more interesting is the context in which this occurred in the discussion. It was in the middle of a discussion in relation to 'What does the phone mean to you?' and the other participants had mentioned how they feel lost without it because they are used to having it with them all the time. This turn of Pasindu occurred immediately afterwards and there is no visible connection between the previous discussion and his explanation of Google maps, except perhaps the reference to feeling 'lost'. Pasindu appears to be using the turn simply to provide information about an interesting feature of the phone rather than contributing to the discussion taking place at the time.

The following is an example of educating others about their own phones from a senior manager group (key section italicised):

Moderator Do you have 3G? [From Ajantha]

Ajantha (M) No.Idon't

Tharanga (M) Your phone should have, those type of phones do

Notice that Ajantha doesn't even express any doubts about whether his phone has $3 \mathrm{G}$ capability. He explicitly states that it does not. However, Tharanga insists that it should have because '...those types of phones do...' Other technophiles also volunteered similar information about the phones of others, but it was usually when the owners expressed some doubt.

The above findings explain how the participants who have been labelled in this study as 'technophiles' established their identity as 'knowledgeable' consumers. However, what is more interesting from the perspective of this paper is how they distinguished their usage patterns of the phone from others they consider as 'basic' users.

\section{The 'Other'vis-à-vis the 'Technophile'}

In constructing 'the other' the technophiles claimed to use more features in more functions than the 'basic' or the 'average' user and also expressed a preference for using features that are not commonly used by others. Sumith, a senior manager, was quite explicit about this preference, and the reason for this preference - self-awareness of superior knowledge compared to others. In the following excerpt he explains why he gets 'a kick' out of using features 'like GPS' (key sections italicised): 


\section{NSBM Journal of Management}

Vol. 1, No. 2, July-December, 2015

Sumith (M) Like when you're at a place which is not familiar to you, if you have GPS, you can see, compare familiar locations with where you are right now. Right? And basically you can educate the others. Like everyone is not aware of maps and grid locations and things like that. Every map has squares. Very hardly, rarely people know why that is. Like, those grid locations, lot of people, like, I mean that they don't know how to read a grid location. So I use that as an educational tool to educate, may be like, when I travel with my family.

Here, notice how Sumith distinguishes himself from the majority users who have less knowledge of the phone - 'everyone is not aware of' and people 'rarely' know things like reading grid locations (of which he has knowledge). This discussion continued further and later he also said, ‘... And just like when you know... how to use it that others don't, certainly you get a kick out of that...' Sumith not only considers he has knowledge of the mobile phone that others don't, but he also enjoys using such features because others don't know how to use them. Much later in the discussion, he revisited the GPS saying, '...I don't use these common features much, like 3G, and everyone uses it. Seriously, I use things like that GPS, no one uses it...' Similarly there were references by other technophiles to 'basic users,' 'average users,' and 'most people' who are content with 'common' or 'basic' features of the phone, whereas they use the phone in more sophisticated ways. Thus, similar to the 'youth' identity, the 'technophile' identity is distinguished by a usage pattern considered by those who construct the identity as unique to them.

\section{Managing Multiple Identities}

Although attention was not paid to this aspect in the previous discussion, it indicates that people do construct more than one identity for themselves: some senior managers constructed both the 'executive' and 'technophile' identities for themselves and some NUMC participants constructed both the 'youth' and 'technophile' identities for themselves. Sometimes, although not in the above situations, such multiple identities can be incompatible with each other. It was evident in the participants' talk that how people use the mobile phone can help in managing such conflicting identities. In the senior managers' talk this took the form of 'juggling' different identities simultaneously, namely, the identity of a 'senior business executive' and that of a 'family member' or that of a 'fun-loving person.' In the talk of the young participants (NUMC only), it took the form of 'transitioning' from a 'youth' identity to a 'future business executive.' 
'I am How I Consume': The Construction of Identity through Use of the Mobile Telephone

\section{Juggling Identities}

Being a business executive and a caring family member are two identities that can easily come into conflict. However, many of the features on the mobile phone that are useful in performing the former identity can also be used in maintaining personal relations. Since these different functions are performed by the same features of the same artefact, the managers vary the usage pattern to assume the 'family member' identity while at work in a manner that does not disrupt the 'executive' activity. This enables them to simultaneously mange two conflicting identities; hence, 'juggling'.

One manager mentioned that he generally keeps his phone in 'mute mode' at meetings and has informed family members to call him repeatedly if they want to contact him on an important matter. The multiple 'missed calls' would signal the importance for him to return the call immediately after the meeting. Another mentioned that he would send an SMS to his wife when she is at work to ask if it was a good time to call. Given the important place occupied by the phone in the identity talk relating to work, the phone is obviously a legitimate artefact for the managers to carry at all times when they are at work. However, by using the phone in a different usage pattern -for maintaining personal relations- they are able to switch to the family member identity even at work, without interrupting the performance of their executive identity.

Another identity that can come into conflict with an executive identity is that of a 'fun-loving person'. Managing these two identities is another instance where varying the usage pattern helps to juggle conflicting identities. As previously noted, most managers stated that they do not use the phone for leisure-related activities. The ones who do use it for such activities spoke of the 'fun/entertainment' function of the phone as subordinate to the 'business' function. However, those managers use the phone to switch to the fun-loving identity when circumstances allow them to 'take a break' from the executive identity while they are at work. In so doing, they use the phone in a different usage pattern, such as playing games or listening to songs, that is not associated with the executive identity.

The subordinate state of 'fun' in relation to 'business' was often signalled in the way managers couched leisure activities in references to work. Further, any references to fun and leisure were usually accompanied by laughter of the speaker, joined by others in the group, signalling that these activities are somewhat 'nonsensical' elements related to the mobile phone and not to be taken too seriously. However, using the phone in different ways allows 


\section{NSBM Journal of Management}

Vol. 1, No. 2, July-December, 2015

them to construct this subordinate identity without harming the superior one. The following is an excerpt that demonstrates how the managers achieve this:
Moderator So, so for you it's [the phone] really something to have fun with?..
Udula (F) Yeah. It takes five minutes [laughs]
Ram (M) I mean you spend lots of time, waiting for lots of things to happen. And, er, I suppose this is quite nice to have. [indicating his phone]
Moderator Mmm. So you listen to songs?
Ram (M) Yeah. Even radio. I mean if it is at that point of time, you switch on the radio. I mean the mobile has a radio. You switch it on then you can be listening whilst you're working, not necessarily while you're waiting. But let's say games are useful when you're waiting for someone.

Udula (F) When you're waiting. Yes.

This is part of a discussion where Udula had previously said she plays games on the mobile phone, prompting the moderator to ask the first question in the excerpt. The 'juggling talk' begins when she says that games take '...only five minutes...' indicating that it's not a time wasting activity. This idea is taken up by Ram and developed further in saying that one spends time '...waiting for things to happen...', which (implicitly) could be used for fun activities. The moderator then turns that implicit comment into a more explicit question by asking if he uses the time to listen to music because he had earlier mentioned that he uses the phone as a '...song depository...' His answer once again shows the ability of assuming the fun-loving identity without disrupting performance of the executive; because he points out that one can listen to music 'while' working, whereas games are useful when one is '... waiting for someone...' Udula agrees readily that this is when one can play games.

Once again, the different usage patterns enable juggling the two identities. Due to its role as a 'business tool' the phone is an artefact to have with one when at work. Since it also has features that are related to leisure and fun, one can make use of them when the opportunity arises at work, such as times when one is '... waiting for things to happen...'. This enables switching between executive and fun-loving identities, without disrupting one's work.

This section demonstrates how varying the usage pattern of the mobile telephone helps consumers to manage multiple conflicting identities simultaneously. The next shows that 
'I am How I Consume': The Construction of Identity through Use of the Mobile Telephone

it can also help consumers to smoothly move from one identity to another when they are in transitional stages of their lives.

\section{Transitioning from One Identity to Another}

A number of participants in the NUMC youth groups were in their first jobs, having just completed their undergraduate studies. Some others were doing part-time work while still undertaking undergraduate studies. These youth are beginning to use the phone in their work as well. Further, they anticipate using it in various different ways in the future in relation to their work. They associate different functions of the phone with the identity of a 'youth' and an anticipated 'future executive' identity and change their usage patterns accordingly. These changes are of two kinds: on the one hand, in their future work life as executives they anticipate using new features they currently don't use; on the other, they are discontinuing, or have discontinued, some phone-related practices they used to engage in as youth because they have now started to work. Thus, there is a temporal dimension to the changes in use pattern; hence 'transitioning.'

In constructing a future executive identity, the youth stated that they anticipate using features of the phone that they don't currently use, when they progress in their career. For some of them this is in the near future, as in the case of one boy who said that he is '...now finding the need...' to access email and MS Word documents on the phone. For others, the anticipation is more distant, where they say that they don't currently need certain features, but anticipate that they would need them later. The temporal -anticipatory - nature of these phone uses is demonstrated in the following excerpt which shows that the identity of executive and practices related to it are placed in the future:

Rasika (F) Again, if I get into, like I'm just getting into work and stuff like that and if I get into marketing later on, I probably will be looking at investing in a BlackBerry as well. Because it's just convenient, and I've heard this over and over, and I've seen it. And I'd probably get one of those later on. But it's not again a priority for me right now.

While referring to anticipated new phone uses in the future, the youth also spoke of practices they have discontinued, because they are now starting to work. These practices were often spoken of in terms of altered priorities, e.g., having no time to play games anymore because they are busy with work. In one focus group these were discussed with specific reference to the identity of 'a youth'. In that group two participants - Sahan and Sureni- claimed that they 


\section{NSBM Journal of Management}

Vol. 1, No. 2, July-December, 2015

have now ' ...passed the age...' of being highly concerned about the appearance of the phone, or desiring the latest features that come into the market, with Sahan saying that he used to like 'flashy' phones when he was 'young'. The following is an excerpt from a conversation that occurred a little later. Another participant - Lakmal - had just stated that he had bought a $3 \mathrm{G}$ phone to have video conversations with his girlfriend and that he thought 'it was kind of cool'. None of the others had 3G:

Moderator So you didn't change over? None of you did? And you don't think it's cool or

Sahan (M) Age has passed $[\ldots]$

Sahan (M) Now the age is passed like now we are more into like if we have the opportunity, to go for a professional phone. One that will help us in work.

Here, since Lakmal is the only person who had said he switched to $3 \mathrm{G}$, the moderator asks the others whether they don't think of it as 'cool' and Sahan is quick to respond -'...Age has passed...'. He is clearly referring to the earlier discussion where he had stated that considering any newly introduced feature as desirable or 'cool' was a characteristic of his past youth. He builds on this assertion saying that now he is more interested in '...go[ing] for a professional phone...' that will help him '...in work...'. Note that at this point, the discussion on $3 \mathrm{G}$ is focused on only one of its features -video calls, which Lakmal had referred to in the context of talking to his girlfriend. However, as the discussion continued, he pointed out some other features of $3 \mathrm{G}$ such as faster access to e-mail and Internet. The following occurred immediately after that:

Moderator The others, are the others, you didn't, you were not interested in it? Or you think it's not useful at all?

Sahan (M) The new, the professional phones are 3G enabled. Faster browsing. So if you want to access Internet, e-mail you'll be using $3 \mathrm{G}$ the $3 \mathrm{G}$ network. Not for video

Moderator So when you get a new phone?

Sahan (M) When I get a new handset I'll

Having been reminded that $3 \mathrm{G}$ also has facilities that are useful for work such as e-mail access, Sahan modifies his earlier dismissal of it. However, he qualifies his modified opinion 
'I am How I Consume': The Construction of Identity through Use of the Mobile Telephone

by pointing out that '...professional phones are $3 \mathrm{G}$ enabled...' and that he would like to have it only for work purposes (he had previously mentioned that he is 'finding the need' for e-mail access at work), and not for video calling. These two excerpts together, with previous assertions of having '... passed the age...' of desiring the latest features indicate that Sahan perceives certain practices associated with the phone as the behaviours of a less mature age. These he sees as no longer suitable for him, since he is embarking on a professional life. Now he wants to use the phone for work and plans to acquire a handset with features that will be useful for that purpose. Interestingly, while rejecting some behaviours as belonging to his 'youth', Sahan was enthusiastic about practices such as changing the ringtone to reflect his 'mood' - something expressly named by senior managers as a practice of 'kids'. This indicates the 'transitional' nature of the stage in life that these youth are in, and its implications for phone use.

In summarising all the findings, it is evident that different patterns of using a product could feature in consumers' construction of identity as a form of demarcating one's identity from those of 'others'. Further, consumers also manage multiple identities by varying the consumption pattern of the same product, either to maintain two conflicting identities at the same time, or to transition from one identity to another.

\section{Discussion}

The practices of identity construction through different patterns of consumption, or how one consumes a product, correspond fairly closely to how previous literature has discussed identity construction through the consumption of different consumption items, or what one consumes.

\section{Differentiating Between Identities}

Differentiating between identities takes various forms of inclusion and exclusion (Hall, 2000, Yamada, 2009) that highlight similarities and differences between different identities. The construction of self (inclusion) vs. the other (exclusion) took three forms in this study: first is the identification of certain patterns of consumption as related to a particular identity. This was seen in relation to the executive, youth and technophile identities. Second is the identification of certain usage patterns as unique to a given identity. This too was seen in relation to the above three identities, although it wasn't very prominent in constructing the executive identity. Third is dissociating oneself from certain patterns of consumption as irrelevant or even inappropriate for an important identity. This was seen only in relation to the executive identity. 


\section{NSBM Journal of Management}

Vol. 1, No. 2, July-December, 2015

The first two forms are quite common in the literature relating to the use of different products that symbolise certain identities. For example, the symbolic associations of brands, as well as colours and forms of products with different identities were noted in the literature review (Belk 1988, Fortunati \& Hebdige 1988/2000, Cianchi 2006, Jantzen, et al. 2006). The inclusion and exclusion though different usage patterns, although not in the context of identity, has also been discussed (Holt 1995). Therefore, similar to different products symbolising different identities, different patterns of consumption also seem to symbolise different identities. What is often implied in the in symbolic consumption of products, but not explicitly discussed is that in the identity work related to consumption, '... what we do not want to consume is often as ... important as what we desire...” (Wilk 1997, p. 175, emphasis added). It appears that this is also true for how one consumes, when considering the third form of inclusionexclusion practices. In other words, the consumption patterns one does not want to engage in are also symbolic of one's identity.

The technophile identity can also be discussed in relation to Bourdieu's (1984) argument that refined 'taste' in consumption can signal 'distinction' between consumers. In the case of technophiles, although inclusion and exclusion are based on the pattern of consumption, the basis of distinction is superior technological knowledge. This, they claim, enables them to use technologically complex features that others cannot. This usage pattern takes a form of what Holt (2000, p. 241) calls 'connoisseurship', where some consumers accentuate certain aspects of a consumption object that are ignored by others in order to express a personal style, even if the object itself is widely consumed. Through the expression of stylistic individuality, such consumers display their superior knowledge regarding the product category. For example, one consumer in Holt's (2000) study speaks enthusiastically about the vegetable dye that makes a rug beautiful. In a similar fashion, the technophiles in this study display their superior technological knowledge through consumption practices that involve technologically complex features that the average mobile telephone user does not use. Thus, in the case of technophiles, it is not the usage practices per se that construct the distinction between self and the other. In a manner similar to how 'taste' differentials in consuming cultural objects such as paintings are used to signal levels of aesthetic knowledge (Bourdieu 1984), different usage practices are used to signal superior technological knowledge.

\section{Managing Multiple Identities}

The different strategies of managing multiple identities introduced by Ahuvia (2005) can be used to discuss the practices identified in this study. The practice of 'juggling identities' occurs where senior managers manipulate different social functions of the phone to construct 
'I am How I Consume': The Construction of Identity through Use of the Mobile Telephone

a 'family member' or 'fun-loving' identity while at work, without disrupting the 'executive' identity. This is similar to what Ahuvia (2005, p.181) calls 'synthesising', which is a strategy used '.. when an object or consumption activity successfully combines the previously conflicting aspects of the consumer's identity in a way that comes reasonably close to giving the consumer the best of both worlds...' This is precisely what managers do when they use the phone to switch between the 'executive' identity and the 'family member' or 'fun-loving' identity. They are attempting to assume one of the latter two identities without disrupting that of the executive, thereby having 'the best of both worlds'. However, Ahuvia (2005) relates synthesising to consumption situations where objects simultaneously symbolise two conflicting identities: for example, collecting vintage cigarette cases that symbolise both decorative femininity and self-assured feminist figures of the post-1960s. In such situations there is no change in the manner of consuming the object; rather, it carries two symbolic meanings simultaneously. This study shows that 'juggling' identities involves varying the usage practice at appropriate moments. It is this synthesising practice rather than symbolic synthesis that helps to manage multiple identities simultaneously.

The practice of 'transitioning' cannot be fitted comfortably into any one of the categories proposed by Ahuvia (2005); it appears to be a combination of two strategies - 'demarcating' and 'synthesising' (Ahuvia, 2005, p, 181). Demarcating occurs when selective consumption (i.e. consuming some objects and rejecting others) is used to accentuate a preferred identity out of two conflicting alternatives. For example, Ahuvia (2005) speaks of one of his research participants who desired to be a composer but had to settle for the less risky career of a business woman. The consumption objects she claims to 'love' emphasise the former and downplay the latter, thereby 'demarcating' between the desired identity of a composer and the rejected business woman identity. Similarly the NUMC youths' practices of 'transitioning' indicate that they are beginning to reject (through phasing out) some of the entertainmentrelated phone uses which they see as practices of a 'youth' and not compatible with the professional identity they are beginning to build; at the same time, they are adopting new business related practices more in line with the desired future identity of an executive. Through this dual process of phasing out some practices and adopting new ones they are temporally 'demarcating' the boundary between the older identity of 'youth' and the new desired identity of 'future executive'. However, in this process there are also indications of synthesising because phasing out is not a complete rejection. Some (in fact, many) of the phone uses of these participants still relate to a 'youth' identity, although such practices are gradually being phased out in favour of new 'business-related' ones. Since they engage in both types of practices at present, to some extent these youth are having 'the best of both worlds', and hence, synthesising. 
The transitioning practice is a strategy adopted in a particular type of multiple identity management, namely, managing the identity conflict occurring at a 'liminal' stage of life (Turner 1969/2002, p. 359). Similar to Turner's (1969/2002, p. 359) description, the NUMC youth in this study are in a 'betwixt and between' position in life where they are neither executives yet nor the youth they used to be, since they are now embarking on a working life. This kind of liminal stage is an ambiguous state and is considered as a position that provides an individual with few tools to construct one's identity because it is stage where one 'passes through a cultural realm that has few or none of the attributes of the past or coming state' (Turner 1969/2002, p. 359). However, the youth in this study deploy different usage patterns of the phone associated with both the past and the coming states in order to negotiate the liminal stage. Thus, rather than being bereft of any cultural means of constructing an identity for themselves, they are using consumption patterns to integrate parts of both the past and the future identities to manage the transition. Given the above discussion, it appears that rather than attempting to categorise this consumption practice under the different categories proposed by Ahuvia (2005), who does not refer to liminal identities, 'transitioning' can be considered a newly identified strategy used by consumers in managing multiple identities.

In summary, it can be concluded that the findings of this study can be theorised, by and large, through concepts available in relation to identity work through consumption. However, at least one pattern of multiple identity management by consumers requires a new concept -'transitioning', which combines the explanations given in some available concepts.

\section{Conclusion}

This study addressed a previously identified weakness of research on consumption-identity relations, which have been blamed for reducing the complexities of objects in use to the mere symbolic meanings they embody (Slater \& Miller 2007). In so doing, this research examined how varying consumption patterns of a single product could feature in consumer identity construction. The findings of the study have implications for both marketing practice and theory, and also opens avenues for further indepth study of 'products in use.'

\section{Implications \& Further Study}

From a practical perspective, the findings of this study have several implications for advertising. Advertisements often depict the identities of their users, and in some cases, especially in the advertisements of mobile telephones, depicting different identities in relation to different usage patterns can also been seen (Wijetunga, 2010). However, this study indicates that consumers utilise diverse usage patterns to manage multiple identities 
'I am How I Consume': The Construction of Identity through Use of the Mobile Telephone

in diverse ways. Marketers could make use of these practices in crafting their advertising messages, for example, by highlighting the usefulness of being able to perform diverse social functions with the phone, and thereby manage different identities in one's life.

The use of the phone in transitioning from one identity to another has implications for mobile service providers. They could utilise a strategy of branding varied service features along the concept of 'customer equity', which refers to the lifetime value of a customer across the brands of a company rather than 'brand equity', which is the customer's assessment of a single brand's intangible qualities (Rust, Zeithaml \& Lemon 2004, p. 113). By focusing on customer equity, service providers can develop a range of service feature brands with narrowly defined brand images with a view to captur the shifting usage patterns and preferences over time with different brands, thereby developing long-term service relationships with consumers (Rust et al. 2004). In doing this, especially in relation to transitioning into adulthood, it is possible to use narratives of 'rites of passage'. The literature indicates that using some products such as high- heeled shoes for women, signal the move from childhood to adulthood (Belk 2003). A variant of this theme could be used in presenting different service features as becoming more important as you move into adulthood.

In terms of theory, this study contributes to the large body of literature on the use of consumption for identity construction.. It demonstrates that varying patterns of consumption of the same object are implicated in complex ways in consumers' identity construction processes. However, the specific patterns of how meanings related to identity are constructed within social relations need to be further examined. For example, doing various things to and with the mobile telephone was identified as a key social activity in constructing a youth identity; however, there remains a need to study in-depth how the meaning making takes place within specific social relations among young users.

Although such further examinations are required, this study establishes clearly that not only what one consumes, but also how one consumes can play a role in consumer identity construction.

\section{References}

Agar, J 2003, Constant touch: A global history of the mobile phone. Icon Books, Cambridge, UK:

Ahuvia, AC 2005, 'Beyond the extended self: loved objects and consumers' identity narratives', Journal of Consumer Research, vol. 32, pp. 171-184.

Arnould, EJ \& Thompson, CJ 2005, 'Consumer culture theory (CCT): twenty years of research', Journal of Consumer Research, vol. 31 no. 4, pp. 868-882. 


\section{NSBM Journal of Management}

Vol. 1, No. 2, July-December, 2015

Barbour, R 2007, Doing focus groups, Sage, London.

Bauman, Z 2001, 'Consuming life', Journal of Consumer Culture, vol. 1, no.1, pp. 9-29.

Bauman, Z 2007, Consuming life, Malden, MA: Polity.

Belk, RW 1988, 'Possessions and the extended self', Journal of Consumer Research, vol.15, no. 2, pp. $139-168$.

Belk, R W 2003, 'Shoes and self', Advances in Consumer Research, vol. 30, pp. 27-33.

Bourdieu, P 1984, Distinction: A social critique of the judgement of taste (R. Nice, Trans.), Routledge, London.

Braun, V \& Clarke, V 2006, 'Using thematic analysis in psychology', Qualitative Research in Psychology, vol. 3, pp. 77-101.

Braun, V \& Clarke, V 2013, Successful qualitative research: a practical guide for beginners, Sage, London.

Carroll, JS, Howard, S, Peck, J \& Murphy, J 2002, 'A field study of perceptions and use of mobile telephones by 16 to 22 year olds', The Journal of Information Technology Theory and Application, vol. 4, no. 2, pp. 49-61.

Dittmar, H 2008, Consumer culture, identity, and well-being: the search for the 'good life' and 'body perfect', Psychology Press. New York.

Featherstone, M 2007, Consumer culture and postmodernism, 2nd edn, Sage, London.

Firat, AF \& Venkatesh, A 1995, 'Liberatory postmodernism and the reenchantment of consumption, Journal of Consumer Research, vol. 22, pp. 239-267.

Fortunati, L \& Cianchi, A 2006, 'Fashion and technology in the presentation of the self', in J. R. Hoflich \& M. Hartmann (eds), Mobile communication in everyday life: ethnographic views, observations and reflections, pp. 203-226, FFrank \& Timme, Berlin.

Gould, SJ \& Lerman, DB 1998, "”ostmodern" versus "long-standing" cultural narratives in consumer behavior: an empirical study of netgirl online', European Journal of Marketing, vol. 32, nos. 7-8, pp. 644-654.

Hall, S 2000, 'Who needs 'identity'?' in P Du Gay, J Evans \& P Redman (eds), Identity: a reader, pp. 15-30, Sage, London.

Hebdige, D. (1988/2000). 'Object as image: the Italian scooter cycle', in J. B. Schor \& D. B. Holt (eds), The consumer society reader, pp. 117-154, New York: The New Press.

Hill, RP 2002, 'Consumer culture and the culture of poverty: implications for marketing theory and practice', Marketing Theory, vol. 2, no. 3, pp. 273 - 293.

Holt, DB 1995, 'How consumers consume: a typology of consumption practices', Journal of Consumer Research, vol. 22, no. 1, pp. 1-16.

Holt, DB 2000, 'Does cultural capital structure American consumption?' in J. B. Schor \& D. B. Holt (eds), The consumer society reader, pp. 212-252, The New Press, New York. 
'I am How I Consume': The Construction of Identity through Use of the Mobile Telephone

Holt, DB \& Schor, J B 2000, 'Introduction: do Americans consumer too much?' in J. B. Schor \& D. B. Holt (eds), The consumer society reader (pp. vii-xxii), The New Press, New York.

Jantzen, C, Østergaard, P \& Sucena Vieira, CM 2006, 'Becoming a "woman to the backbone": lingerie consumption and the experience of feminine identity', Journal of Consumer Culture, vol. 6, no.2, pp. 177-202.

Kleine III, RE, Kleine, SS \& Kernan, JB 1993, 'Mundane consumption and the self: a social-identity perspective', Journal of Consumer Psychology, vol. 2, no. 3, pp. 209 - 235.

Krueger, RA \& Casey, MA 2000, Focus groups: a practical guide for applied research, 3rd edn, Sage, London.

Lee, MJ 1993, Consumer culture reborn: the cultural politics of consumption, Routlege, London.

Lee, MJ 2000, Introduction, in MJ Lee (ed), The consumer society reader, (pp. ix-xxvi), Blackwell Oxford, UK.

Liyanage, U 2009, Profiling the Sri Lankan consumer: multiple portraits and manifest patterns, 3rd edn, Postgraduate Institute of Management, Colombo, Sri Lanka

Miles, S 1998, Consumerism as a way of life, Sage, London.

Ritzer, G \& Slater, D 2001, Editorial, Journal of Consumer Culture, vol. 1, no. 5-8.

Rust, RT, Zeithaml, VA \& Lemon, KN 2004, 'Customer-centered brand management', Harvard Business Review, vol. 82, no. 9, pp. 110-120.

Shankar, A, Elliott, R, \& Fitchett, J 2009, 'Identity, consumption and narratives of socialization'. Marketing Theory, vol. 9 no. 1, pp. 75-94.

Slater, D 1997, Consumer culture and modernity, Polity Press, Oxford, UK.

Slater, D 2005, 'The sociology of consumption and lifestyle', in C Calhoun, C Rojeck \& B Turner (eds), The Sage handbook of sociology, pp. 174-187, Sage, London.

Slater, D \& Miller, D 2007, 'Moments and movements in the study of consumer culture: a discussion between Daniel Miller and Don Slater', Journal of Consumer Culture, vol. 7, no. 1, p. 5.

Therkelsen, A \& Gram, M 2008, 'The meaning of holiday consumption: construction of self among mature couples', Journal of Consumer Culture, vol. 8, no. 2, pp. 269-292.

Thompson, C 2014, 'The politics of consumer identity work', Journal of Consumer Research, vol. 40, no. 5, pp. iii - vii.

Turner, V 1969/2002, Liminality and communitas, in M Lambek (ed.), A reader in the anthropology of religion, pp. 358-374, Blackwell, Malden, MA.

Vesa, J 2005, Mobile services in the networked economy, IRM Press, Hershey, PA.

Wijetunga, D 2010, A consumer culture perspective on the social shaping of an 'unstable' technological artefact: a Sri Lankan study of the mobile telephone, PhD Thesis, The University of Melbourne, Melbourne.

Wilk, R 1997, 'A critique of desire: Distaste and dislike in consumer behaviour', Consumption, markets and culture, vol. 1, no.2, pp. 97-196. 
NSBM Journal of Management

Vol. 1, No. 2, July-December, 2015

Yamada, M 2009, Westernization and cultural resistance in tattooing practices in contemporary Japan, International Journal of Cultural Studies, vol 12, no. 4, pp. 319-338.

Ybema, S, Keenoy, T, Oswick, C, Beverungen, A, Ellis, N \& Sabelis, I 2009, Articulating identities. Human Relations, vol. 62, no. 3, pp. 299-322. 